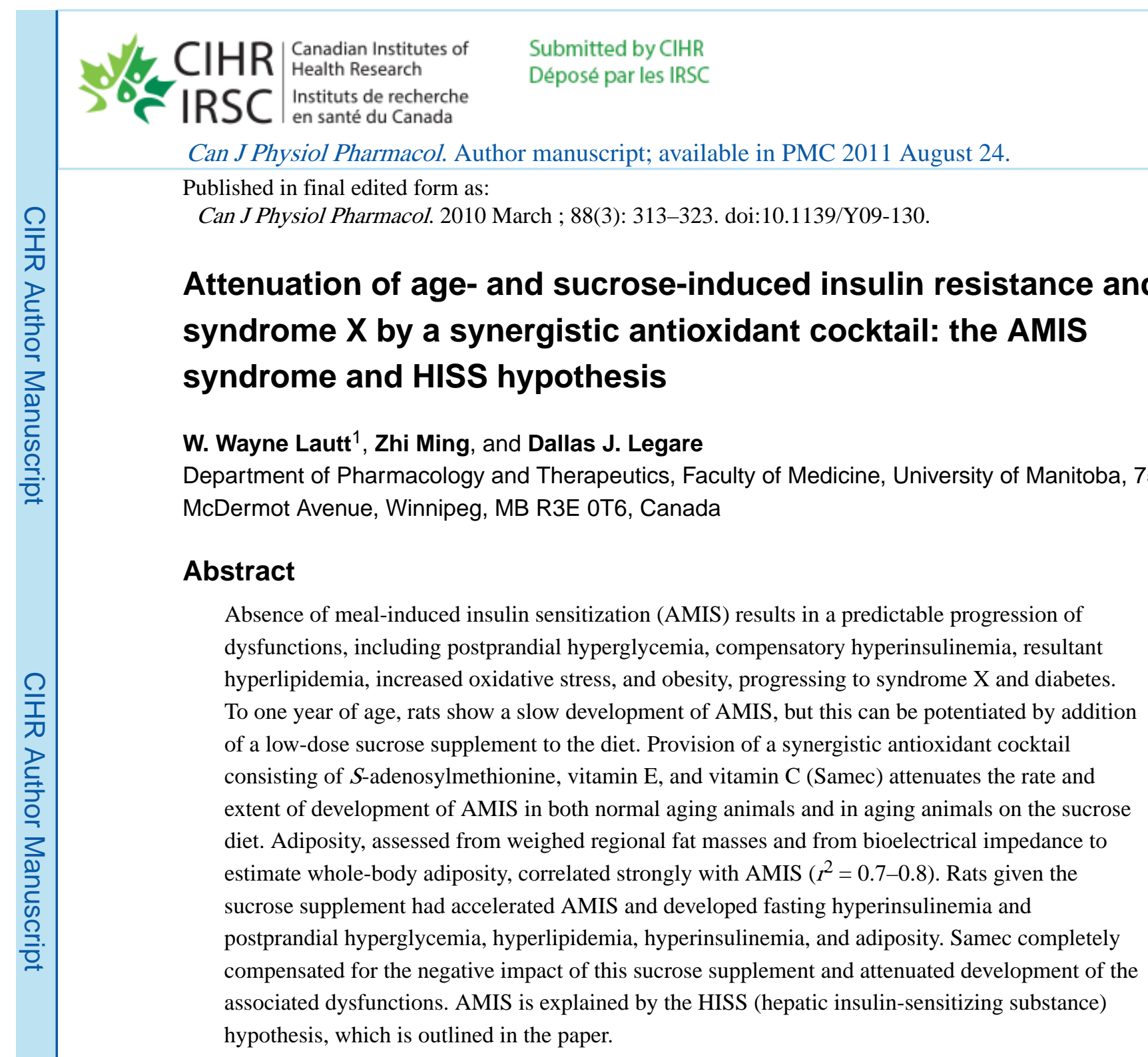

\title{
Keywords
}

HISS; AMIS; MIS; cardiometabolic risk; preventative; obesity; adiposity; diabetes; Samec

This paper was presented at the Canadian Oxidative Stress Consortium meeting held in Winnipeg in May 2009. The central message of the talk was that hepatic insulin-sensitizing substance (HISS)-dependent insulin resistance (HDIR) results in absence of meal-induced insulin sensitization (AMIS) and leads to progressive and predictable homeostatic dysfunctions. AMIS, if chronic, results in the AMIS syndrome. A second message was that the control of meal-induced insulin sensitization (MIS) by 2 feeding signals allows for pharmaceutical restoration of MIS in diabetic models as a first-in-kind therapeutic treatment for prediabetic insulin resistance, syndrome $\mathrm{X}$, and obesity. This paper is based on 3 recent publications that used a synergistic antioxidant cocktail as a research tool to test the AMIS syndrome and HISS hypothesis.

\footnotetext{
${ }^{1}$ Corresponding author wlautt@ cc.umanitoba.ca.
} 


\section{The HISS hypothesis}

After a meal, the dynamic glucose disposal response to insulin is increased by at least $100 \%$. In the fed state, a pulse of insulin will result in the release of a pulse of HISS from the liver (Fig. 1). HISS action is selective for skeletal muscle and leads to uptake and storage of glucose as glycogen in the large skeletal muscle mass. HISS release in response to insulin occurs only in the presence of 2 permissive feeding signals, the first being a hepatic parasympathetic-mediated signal (reviewed by Lautt 2004) and the second being a 30\%50\% elevation in hepatic glutathione (GSH) levels (Guarino and Macedo 2006; W.W. Lautt, J. Schafer, M.P. Macedo, and D.J. Legare, submitted). Although HISS has not been chemically characterized, its dynamic action and hormonal nature are readily quantified (reviewed by Lautt 2003).

For MIS to be quantified, an index of insulin sensitivity must be used that can be obtained in both the fed and fasted state. MIS has been shown by using changes in arteriovenous glucose gradients (glucose extraction) across various organs, the insulin tolerance test, and the rapid insulin sensitivity test (RIST).

The RIST is a rapidly sampled transient euglycemic clamp in response to a bolus administration of insulin. The operating procedure for the RIST has been described (Lautt et al. 1998), and methods for differentiating and quantifying HISS-dependent and HISSindependent insulin actions have been reviewed (Lautt 2003). The RIST index is the amount of glucose that must be infused to maintain a euglycemic baseline after a bolus administration of insulin.

When MIS does not occur, feeding results in postprandial hyperglycemia and a compensatory increase in insulin secretion. Direct insulin action primarily affects adipose tissue and liver. The liver has a limited glycogen storage capacity; therefore, beyond the saturation point, additional glucose taken up by the liver is converted to triglycerides and results in transport of fat through very low density lipoproteins (VLDL) for storage in peripheral tissues. By this process, AMIS results in a progressive increase in adiposity. The postprandial hyperglycemia, hyperinsulinemia, and hyperlipidemia have all been shown to produce free radicals and each has been shown to be an independent risk factor for the development of cardiovascular disease (reviewed by Lautt 2007). Virtually all of the complications associated with diabetes have been attributed to increased free radical production (Brownlee 2001), which is also associated with the normal process of aging.

\section{Meal-induced insulin sensitization (MIS)}

MIS is a readily quantified phenomenon that has only recently been identified (Lautt 1999; Lautt et al. 2001; Sadri et al. 2006; Patarrão et al. 2008). MIS is illustrated by the dramatic increase in the glucose disposal response to insulin immediately after a meal. The concept of MIS is derived from the observation that the dynamic response to insulin, determined after a $24 \mathrm{~h}$ fast, is at least doubled when tested $100 \mathrm{~min}$ after administration of a mixed meal in rats (Sadri et al. 2006) and humans (Patarrão et al. 2008). The process of MIS is a result of the action of HISS, which is released from the liver in response to a pulse of insulin and acts 
selectively to stimulate glucose uptake in skeletal muscle (Xie and Lautt 1996). In Fig. 2A, the rate of glucose infusion required to maintain euglycemia is shown for healthy male volunteers after administration of a bolus of $50 \mathrm{mU} / \mathrm{kg}$ insulin in the $24 \mathrm{~h}$-fasted state. This RIST was repeated $100 \mathrm{~min}$ after consumption of a mixed test meal. The RIST index increased from $215.5 \pm 20.8 \mathrm{mg} / \mathrm{kg}$ to $681.2 \pm 60.9 \mathrm{mg} / \mathrm{kg}$ due to the action of HISS, which is shown in Fig. 2B as calculated by subtracting the fasted RIST profile from the fed profile. The RIST index reveals a distinctive pulsatile action beginning $6.3 \mathrm{~min}$ after insulin administration and continuing for $48 \mathrm{~min}$ beyond the direct action of insulin.

MIS can be quantified using 2 different approaches, as shown in Fig. 3 (from Sadri et al. 2006). A RIST index is determined first after a $24 \mathrm{~h}$ fast, in which HISS release is minimal or absent (Lautt et al. 2001). The existence of MIS is then demonstrated by carrying out the RIST approximately $100 \mathrm{~min}$ after administration of a mixed meal, and after a new glycemic baseline has been established. In Fig. 3, the study was carried out in conscious rats administered a mixed liquid test meal directly into the stomach through an implanted catheter. The difference in RIST index between the $24 \mathrm{~h}$-fasted and fed state is attributed to HISS action on skeletal muscle. A similar degree of MIS can be demonstrated in conscious animals that have voluntarily consumed a meal of normal rat chow (Latour and Lautt 2002).

The second method to quantify MIS is to determine the RIST index in the recently fed state and then again after HISS release has been blocked by any of several means known to interfere with the feeding signals (Lautt et al. 2001). In Fig. 3, MIS is completely blocked by intravenous administration of atropine, which acts on muscarinic receptors in the liver to block HISS release. From this figure it can be seen that quantification of MIS is similar using either method, as the increased MIS comparing fasted with fed RIST is completely reversed by atropine. The most technically straightforward method for differentiating the HISS component in animal studies is to allow feeding in the conscious state and to then carry out the tests with the animals under anesthesia before and after blockade of HISS release. Once developed in the conscious state, the RIST index is not altered by anesthesia (Latour and Lautt 2002). Testing in humans, however, is (so far) restricted to testing before and after a meal. A means of completely blocking HISS release in humans has not been demonstrated, although $0.5 \mathrm{mg}$ atropine in humans blocked approximately $56 \%$ of HISS release (Patarrão et al. 2008).

HISS release from the liver is dependent upon the arrival of 3 simultaneous signals. Two permissive feeding signals are required to be delivered to the liver. One signal is an elevation of hepatic GSH levels, which increase by 30\%-50\% after a meal (Tateishi et al. 1974;

Guarino et al. 2003; W.W. Lautt, J. Schafer, M.P. Macedo, and D.J. Legare, submitted). The second signal is delivered by the hepatic parasympathetic nerves, which release acetylcholine that acts on muscarinic receptors (Xie and Lautt 1995; Lautt et al. 2001), resulting in activation of nitric oxide synthase and generation of nitric oxide (Sadri and Lautt 1998, 1999; Guarino et al. 2003). Either signal alone is not sufficient (Guarino and Macedo 2006; W.W. Lautt, J. Schafer, M.P. Macedo, and D.J. Legare, submitted). In the presence of these 2 feeding signals, a pulse of insulin (the third signal) results in the release of a pulse of HISS. 
Both feeding signals can be mimicked by using repurposed pharmaceuticals. Bethanechol mimics the parasympathetic signal and $N$-acetylcysteine mimics the GSH signal. Provision of both drugs to fasted rats results in sensitization to insulin at levels similar to those seen in fed rats. In the rat model of sucrose-induced diabetes, in which MIS does not occur, it appears that both feeding signal pathways are impaired because neither bethanechol nor $N$ acetylcysteine alone restored MIS, whereas both drugs together restored the ability of a meal to result in HISS release (W.W. Lautt, J. Schafer, M.P. Macedo, and D.J. Legare, submitted).

The drug combination of bethanechol (a cholinergic agonist) plus $\mathrm{N}$-acetylcysteine (to elevate GSH) has undergone phase 2 clinical trials, and a press release from DiaMedica Inc. has reported that 12 weeks of placebo-controlled and blinded drug administration before each meal resulted in reduced $\mathrm{HbA}_{1 \mathrm{c}}$, fructosamine, and body weight, consistent with the HISS hypothesis.

\section{Absence of meal-induced insulin sensitization (AMIS)}

Blocking HISS release prevents the development of MIS in response to a meal and also blocks MIS once it has been developed (Sadri et al. 2006). HISS-dependent insulin action accounts for 55\% of the response to a pulse of insulin in the fed rat (Lautt et al. 2001), 45\% in fed mice (Latour and Chan 2002), and 67\% in fed humans (Patarrão et al. 2008). HISS action decreases progressively with the duration of fasting to become insignificant after a 24 $h$ fast. In the absence of HISS release, a state of HDIR is said to exist. While HDIR is appropriate in the fasted state to reduce the hypoglycemic impact of insulin, HDIR in the fed state results in AMIS. We have suggested that AMIS represents the earliest metabolic deficiency that leads to a definable and predictable series of consequences including syndrome $\mathrm{X}$ and diabetes (Lautt et al. 2008).

The normal response to a meal results in a greatly amplified response to insulin secondary to HISS acting on skeletal muscle (Xie and Lautt 1996; Moore et al. 2002), leading to nutrient energy storage primarily as glycogen in skeletal muscle. When HDIR results in AMIS, however, the postprandial condition is typified by hyperglycemia, compensatory hyperinsulinemia, resultant hyperlipidemia, and increased free radical production. AMIS results in a homeostatic shift from nutrient storage as glycogen to storage as fat. We have suggested that HDIR and the resultant AMIS could account for the cardiovascular and other risk factors associated with insulin resistance, obesity, and diabetes (Lautt 2007; Lautt et al. 2008; Ming et al. 2009). Because AMIS results in a mechanistic-based, predictable, and manipulatable progression of dysfunctions, we suggest it could be referred to as an AMIS syndrome.

\section{The AMIS syndrome}

The AMIS syndrome describes the same cluster of dysfunctions that has been given at least 10 other names, including syndrome $\mathrm{X}$, metabolic syndrome, insulin resistance syndrome, dysmetabolic syndrome, plurimetabolic syndrome, cardiometabolic syndrome, dyslipidemic hypertension, hypertriglyceridemic waist, and deadly quartet (Grundy et al. 2005). The most recent renaming was done by the American Diabetes Association (ADA) in 2006 when they 
referred to it as cardiometabolic risk (Stern and Izkhakov 2006). None of these previous names have a mechanistic base. Notably, the most recent name diminishes the importance of the impact of this metabolic syndrome on systems other than the cardiovascular system.

According to the AMIS syndrome hypothesis, a cluster of predictable dysfunctions arises from the progressive accumulation of the impact of AMIS that occurs with each meal. A series of experiments was designed to test the relationship between MIS, HISS action, and the AMIS syndrome. Diets high in refined sugars, including sucrose, fructose, and glucose, result in increased oxidative stress. Although the dysfunctions associated with insulin resistance have been attributed to damage induced by free radicals, clinical trials for antioxidants have generally been unimpressive. Most trials used 1 or 2 antioxidants, often combining vitamins $\mathrm{C}$ and $\mathrm{E}$. We reasoned that an antioxidant would be of most value if all areas of the cell were targeted. We developed a synergistic cocktail of antioxidants (Ming et al. 2006) consisting of $S$-adenosylmethionine to stimulate the production of hepatic GSH, vitamin $\mathrm{E}$ to quench free radicals in the lipid component of the cell, and vitamin $\mathrm{C}$ to act in the aqueous phase. Given separately, neither vitamins $\mathrm{C}$ and $\mathrm{E}$ nor $S$-adenosylmethionine protected against the toxic effect of thioacetamide, a hepatotoxin known to produce dysfunction due to oxidative stress. The combined compounds, on the other hand, protected against liver inflammation and impairment of HISS action. This combined cocktail, referred to as Samec, provides protection against the development of AMIS and the resultant AMIS syndrome dysfunctions that are seen with normal aging and that are exacerbated by the consumption of sucrose. Rats were tested over a one-year period of aging, with and without a low-dose sucrose supplement (5\% in drinking water) and with subgroups also receiving oral supplementation of the antioxidant cocktail Samec administered through the food. Samec protected HISS action attributed to aging and eliminated the negative effect of the low-dose sucrose diet. The degree of suppression of HISS action correlated with adiposity and postprandial metabolic dysfunctions.

\section{Age and AMIS}

Age is associated with an increased risk of insulin resistance and type 2 diabetes (Singh and Marshall 1995; Dela and Kjaer 2006). Aging is also associated with a decrease in lean body mass and a relative increase in fat mass, and it has been suggested to result in a slow progressive redistribution of fat from subcutaneous tissue to central abdominal tissue (Borkan et al. 1983; Barbieri et al. 2001). Aging is also associated with a generalized reduction in parasympathetic nerve function demonstrated for the cardiovascular system (O’Brien et al. 1986; Ingall et al. 1990; Corbett et al. 2007), eyes (Fitzgerald et al. 2005; Tewari et al. 2006; Jablonski et al. 2007), GI tract (Phillips and Powley 2001, 2007), and urinary bladder (Schneider et al. 2005). Parasympathetic dysfunction can be identified before development of diabetes (Lautt 1980), is later associated with the metabolic syndrome (Britton et al. 2007) and obesity (Skrapari et al. 2007; von Känel et al. 2007), but improves with reduced adiposity (Mager et al. 2006). Aging in Wistar rats results in insulin resistance that can be accounted for by HDIR (Ribeiro et al. 2008). The HISS component of insulin action was reduced from 53\% of the total response to a pulse of insulin in 9-weekold rats to $18 \%$ at 1 year. The direct action of insulin was not altered. 
While it is well recognized that adiposity and insulin resistance are related, cause versus effect remains controversial (reviewed Robinson and Graham 2004), as does the relationship between insulin resistance and regional adiposity. Many studies claiming a relationship between abdominal obesity and insulin resistance measured only abdominal obesity or its surrogate indicator, waist circumference. These studies imply but do not clarify the issue of selective roles for regional adiposity. While a special role has been proposed for adipose tissues that release lipids directly to the liver via the portal vein (Björntorp 1992; Goran et al. 2001; Lebovitz 2003; Lindmark et al. 2005), others have failed to show any special role for this portal theory (Frayn 2000) or for selective regional adiposity (Goodpaster et al. 1997; Taniguchi et al. 2002; Tulloch-Reid et al. 2004).

The free radical theory of aging, first proposed by Harman (1956), suggests that endogenous free radicals continuously and progressively cause permanent mitochondrial damage (Sastre et al. 1996; Cadenas and Davies 2000). The capacity to scavenge reactive oxygen species decreases with age (Esteve et al. 1999; Rebrin et al. 2004). While insulin resistance results in excess free radicals, reactive oxygen species are also proposed as a trigger for insulin resistance in numerous settings (Houstis et al. 2006). Approximately $300 \mathrm{~L}$ of oxygen is required to regenerate ATP in a healthy human consuming $2100 \mathrm{kcal}$ per day. Since the human body contains only about $100 \mathrm{~g}$ of ATP, and ATP usage is estimated at $75 \mathrm{~kg} / \mathrm{day}$, ATP should be regenerated 750 times per day, predominantly as oxidative phosphorylation (Inoue 1994). Under physiological conditions, about 3\%-10\% of molecular oxygen is converted to reactive oxygen species (Chance et al. 1979). A variety of agents protects the liver against the ravages of reactive oxygen species through the actions of a number of scavengers, including superoxide dismutase, catalyse, GSH, GSH peroxidase, vitamin E, uric acid, and ascorbic acid. Under physiological conditions, $15 \%, 45 \%, 35 \%$, and $5 \%$ of the reactive species are generated by mitochondrial, microsomal, peroxisomal, and cytosolic compartments, respectively (Chance et al. 1979). The impact of age on MIS and the impact of the antioxidant cocktail Samec on age-related AMIS are used as one component of the test of the AMIS syndrome hypothesis.

\section{AMIS and a sugar diet}

A sucrose-supplemented diet is capable of generating free radicals through several pathways. The impact of an increase in plasma glucose on oxidative stress is well documented. In the presence of trace amounts of transition metals $\left(\mathrm{Cu}^{2+}\right.$ and $\left.\mathrm{Fe}^{3+}\right)$, glucose will undergo autoxidation that results in free radical generation and leads to the chemical modification of proteins (Wolff et al. 1989; Hunt et al. 1988, 1990). This process has been termed autoxidative glycosylation. The free radicals produced from this process include superoxide, hydroxyl radical, and hydrogen peroxide. All can damage proteins through crosslinking fragmentation. The peroxidation in phosphatidylcholine liposomes and lowdensity lipoproteins (LDL) is also associated with glucose autoxidation (Hunt et al. 1990). It is widely accepted that the autoxidative glycosylation process plays an important role in the pathophysiology associated with diabetes and aging.

When sucrose is offered to rats as a supplement in the drinking water (35\%), HISS action becomes absent within 2 weeks; after 9 weeks of administration, early symptoms of the 
AMIS syndrome, including increased body weight, mild hypertension, and postprandial hyperglycemia, are discernable (Ribeiro et al. 2005). The ability of the sucrose supplement to impair the MIS process through interruption of HISS release is independent of caloric load, as shown by the ability of isocaloric sucrose to result in a degree of HDIR similar to that seen with the liquid sucrose supplement. Because the $35 \%$ sucrose supplement produced such a rapid and complete level of HDIR, we decided that this percentage would not be effective in eliciting a wide enough range of dysfunctions in the models of the AMIS syndrome to afford reasonable correlation statistics between the degree of AMIS and the extent of the predicted dysfunctions.

Initially the rats for the long-term study were offered an alternative water source containing 5\% sucrose. Preliminary tests showed that although adult rats normally drink less than 40 $\mathrm{mL}$ of water per day, they would drink more than $100 \mathrm{~mL}$ per day if $5 \%$ sucrose water was provided. To avoid the homeostatic consequences of long-term overdrinking, only $50 \mathrm{~mL}$ of $5 \%$ sucrose water was provided per rat per day along with free access to tap water. A group of normal aging rats and a group of aging rats given the 5\% sucrose supplement received normal rat chow throughout the one year of aging. An additional 2 groups of animals were aged with and without the sucrose supplement, but received Samec through the rat chow. Given the average daily food consumption of $20 \mathrm{~g}$, the approximate daily intake for vitamin C was $250 \mathrm{mg} / \mathrm{kg}$ body weight, for vitamin E was $30 \mathrm{mg} / \mathrm{kg}$, and for $S$-adenosylmethionine was $19 \mathrm{mg} / \mathrm{kg}$. Blood samples were drawn from $12 \mathrm{~h}$-fasted rats 2 weeks before the metabolic testing to minimize stress. The metabolic testing was done in animals that had been fasted for $8 \mathrm{~h}$ and then allowed to re-feed for $2 \mathrm{~h}$ to ensure a common postprandial state in all tested animals. The degree of HISS action was calculated from the active dynamic response of insulin, determined in the anesthetized state in these fed rats before and after atropine administration (Sadri et al. 2006) (Fig. 3).

\section{HISS action affected by age, sucrose supplementation, and Samec}

The RIST index in young (9-week-old) rats decreased dramatically from $175 \pm 7 \mathrm{mg}$ of glucose per kilogram to $100 \pm 6 \mathrm{mg} / \mathrm{kg}$ by 6 months of age and further to $79 \pm 4 \mathrm{mg} / \mathrm{kg}$ by 12 months, with the HISS-dependent component accounting for virtually all of the decrease. HISS action accounted for $52 \% \pm 2 \%$ of the response to insulin in young animals but decreased to $30 \% \pm 3 \%$ at 6 months and $17 \% \pm 3 \%$ by 12 months (Fig. 4 ).

Figure 5 shows the detrimental effect of the low-dose sucrose supplement on absolute HISS action, and the protective effect of the antioxidant cocktail administered concomitantly with the sucrose supplement. The antioxidant cocktail attenuated the decrease in the HISS component, which remained at $44 \% \pm 2 \%$ and $41 \% \pm 2 \%$, respectively, at 6 and 12 months of age. The effects on the HISS-independent component of insulin action were quantitatively minor and the impact on the RIST index could be accounted for almost entirely by changes in the HISS component of insulin action.

The hypothesis that HISS action inversely relates to adiposity was critically tested by the data shown in Fig. 6 where HISS action and adiposity (whole-body fat content as measured by electrical impedance and confirmed by measurement of regional fat depots from 
perinephric, perienteric, and epididymal masses) are shown. These data were pooled for several groups including older rats (aged to 6 and 12 months) and rats that had supplements of sucrose and antioxidant combinations at each age. Considering the diversity of long-term interventions, the correlation is remarkable. Adiposity can be predicted from determination of the HISS component of insulin action. There was no evidence of a unique effect or role for regional fat, as fat in the whole body and weighed fat from tissues draining into the portal vein (perienteric) or vena cava (epididymal and perinephric) increased in parallel.

HISS action correlated with other components associated with the metabolic syndrome. Fasting glucose, insulin, triglyceride, and total cholesterol levels, as well as postprandial insulin and glucose levels, correlated significantly with HISS action. The antioxidant supplement Samec afforded protection against development of AMIS with age and completely prevented the negative effect of sucrose on development of AMIS. Correlation analysis showed that HISS action could be manipulated over a sufficiently wide range to demonstrate significant and strong correlation with parameters associated with the metabolic syndrome, diabetes, and obesity (Lautt et al. 2008; Ming et al. 2009).

\section{Adiposity and HDIR-cause or effect}

The question that arises is whether adiposity causes resistance to HISS or whether HISS resistance causes adiposity. An argument against adiposity causing selective HDIR is based on the observation that the Zucker fatty rat (Afonso et al. 2007) became obese, but both the HISS-dependent and HISS-independent components of insulin action were equally affected. This demonstrates that at least in this leptin-deficient model of obesity, adiposity did not result in a selective impairment of the HISS action. The $35 \%$ isocaloric sucrose supplement resulted in full HDIR with weight gain becoming mildly but significantly elevated (Ribeiro et al. 2005).

The HISS hypothesis predicts that HDIR results in a lipogenic prediabetic state and that HDIR should therefore predict the level of adiposity (with some time delay as fat progressively accumulates). The relationship of HISS action to adiposity is strong (Fig. 5), and although sucrose or the vitamin treatment alter adiposity and HISS action, the slope and intercept of the plot remain constant. The absence of effect on the slope and intercept of this relationship suggest that any impact the antioxidant cocktail had on adiposity was due to protected HISS action and not to an indirect effect whereby adiposity was attenuated by some other mechanism.

The time delay between HDIR and accumulated adiposity is clearly seen by the observation that HISS action had decreased by $66 \%$ in the control and $37 \%$ in the Samec-supplemented group at 6 months, but no significant difference in adiposity was seen at that time. If adiposity caused HDIR, the degree of HDIR should have been similar in the 2 groups. The difference in HDIR would be expected to result in a gradual delayed accumulation of fat that would only become significant after a period of time. By 12 months, HDIR had progressed and HISS action was reduced to only $17.0 \% \pm 2.7 \%$ of the total response to the insulin bolus; Samec conferred $60 \%$ protection of HISS action and $19 \%$ protection against adiposity. It is anticipated that had the protocol been extended to older ages, HDIR would 
have become complete and adiposity would have continued to preferentially occur in the untreated group. On the other hand, if adiposity had caused HDIR, there should be no time delay and both the treated and untreated groups at 6 months of age should have had equal reduction in HISS action.

\section{Other complications of the AMIS syndrome}

There was a progressive increase in several parameters predicted by the AMIS syndrome and these were attenuated by Samec. Postprandial glucose levels were elevated by 12 months and were protected by Samec so that the 12-month levels in the treated rats were not significantly different from the levels in the young rats. Samec did not significantly alter the slope or intercept of the relationship between HISS action and whole-body fat mass, consistent with the hypothesis that Samec acted on adiposity by protecting HISS action (Fig. $5)$.

The Samec supplement attenuated age-dependent dysfunctions, including HDIR and parameters related to the metabolic syndrome. The difference between the mean of a parameter determined for the young 9-week control group and the 12-month untreated group provides a quantitative estimate of the degree of dysfunction at that age. The difference between that parameter determined in the untreated and treated groups represents the degree of protection afforded by Samec and is expressed as percent protection. The mild degree of hyperglycemia was attenuated in the 12-month group, showing 74\% protection against $2 \mathrm{~h}$ postprandial glucose. The postprandial insulin levels were protected by $28 \%$. The fat mass was protected by $19 \%$ and systolic blood pressure was protected by $31 \%$. The total dynamic insulin action (effect of HISS plus insulin) determined in the fed state was protected by $29 \%$. HISS action was reduced from $95 \mathrm{mg} / \mathrm{kg}$ at 9 weeks in the young rats to $15 \mathrm{mg} / \mathrm{kg}$ at 12 months, but only to $40 \mathrm{mg} / \mathrm{kg}$ at 12 months in the supplement group, thus representing a protection of $60 \%$. The HISS-independent component of insulin action was decreased from $80 \mathrm{mg} / \mathrm{kg}$ in young rats to $65 \mathrm{mg} / \mathrm{kg}$ in untreated rats at 12 months and was also protected (33\%) by the Samec treatment (Fig. 5). In summary, in these animals, the antioxidant attenuation of HDIR offered protection against generalized adiposity, hypertension, and postprandial hyperglycemia.

The Samec supplement also attenuated the sucrose plus age-dependent dysfunctions, including HDIR and parameters related to the AMIS syndrome. The same crude protection index as described above for the age-dependent AMIS syndrome parameters was used to calculate the degree of protection afforded by Samec against the combination of aging and sucrose supplement (calculated from Ming et al. 2009, their Table 1). The calculation was based on comparing the extent of the dysfunction that developed in young 9-week-old rats with that of 12-month-old rats who had also received the sucrose supplement. The protection was determined from the difference in the old group that had been treated with Samec and those that were untreated. Fasting $(8 \mathrm{~h})$ levels were protected for glucose (55\%), triglyceride (50\%), insulin (50\%), and HOMA-IR (homeostatic model assessment of insulin resistance) $(57 \%)$. The $2 \mathrm{~h}$ postprandial glucose showed a $75 \%$ protection. The postprandial insulin levels were protected by $66 \%$. The fat mass was protected by $28 \%$ and systolic blood pressure was protected by $41 \%$. Dynamic insulin action determined in the fed state was 
protected by 55\%. HISS action was reduced from $98 \mathrm{mg} / \mathrm{kg}$ at 9 weeks to $4 \mathrm{mg} / \mathrm{kg}$ at 12 months in the sucrose-fed animals but only to $55 \mathrm{mg} / \mathrm{kg}$ at 12 months in the supplemented group, thus representing a protection of $75 \%$. The HISS-independent component of insulin action was decreased from $83 \mathrm{mg} / \mathrm{kg}$ in young rats to $61 \mathrm{mg} / \mathrm{kg}$ in aged rats on the sucrose supplement at 12 months, who were also protected (58\%) by the Samec treatment. The antioxidant cocktail clearly protected against AMIS; however, each component of the cocktail serves multiple roles in metabolism and our data do not allow us to attribute the effectiveness of Samec to the antioxidant characteristics or other synergistic effects. Thus, the Samec treatment conferred protection against the progressive development of HDIR and resultant AMIS, providing significant protection against generalized adiposity, hypertension, and postprandial hyperglycemia, and represented a powerful tool to test the AMIS syndrome hypothesis.

\section{Current status of the AMIS syndrome hypothesis}

Figure 7 illustrates the progression of the AMIS syndrome from the prediabetic state to the point of death. Ineffectiveness of insulin to cause the release of HISS is appropriate in the fasted state, whereby other insulin functions can be maintained by pancreatic insulin secretion and the risk of developing hypoglycemia is dramatically reduced. Only approximately $50 \%$ of insulin released over a $24 \mathrm{~h}$ period is related to meal processing (Boden et al. 1996). Regulation of HISS allows for MIS that greatly potentiates the glucose disposal response to insulin. Glucose is a toxic compound that must be restricted to tolerable levels. The ability of insulin to cause HISS release is essential for postprandial processing of glucose. If feeding does not result in restoration of the ability to release HISS, MIS does not occur and the response to each meal includes postprandial hyperglycemia, hyperinsulinemia, hyperlipidemia, and increased oxidative stress. The cumulative effect of AMIS leads to progressively more severe but predictable dysfunctions. One of the first dysfunctions that is demonstrable is postprandial hyperinsulinemia, which appears to be the most sensitive indicator of AMIS after a single meal. The hyperinsulinemia tips the homeostatic balance of nutrient partitioning away from glycogen storage in skeletal muscle and towards lipid production, thus resulting in postprandial elevations in triglyceride levels that are seen only several hours after a meal. Fasting glucose levels do not increase until the AMIS syndrome has progressed significantly. At that point, fasting glucose, insulin, and lipid levels are increased and adiposity is clearly well underway. The particular ordering of the remaining cumulative dysfunctions shown in Fig. 7 is intended only to indicate that the disease is progressive. The specific temporal relationships or the development of the individual components of the AMIS syndrome have not yet been determined. Ongoing studies indicate that cardiac dysfunction occurs at an earlier stage than we had anticipated, and endothelial vascular dysfunction occurs at a later stage than we had anticipated.

To further test the AMIS syndrome hypothesis, we currently have another large group of rats being followed to age 18 months under similar testing conditions to specifically relate the degree of AMIS to the degree of cardiac and vascular dysfunctions. 


\section{Conclusions and clinical application}

The utility of this synergistic antioxidant cocktail to serve as a preventative measure for AMIS in high-risk subjects is suggested by these studies. On the basis of the HISS hypothesis and the MIS concept, we have also developed drugs that will simultaneously mimic both the parasympathetic nerve feeding signal and the GSH feeding signal and have demonstrated that these 2 signals, when presented to $24 \mathrm{~h}$-fasted rats or to rats with complete AMIS developed in response to the high-sucrose diet, are capable of restoring the response to insulin to the same level as that seen after a meal in normal healthy animals (W.W. Lautt, J. Schafer, M.P. Macedo, and D.J. Legare, submitted). These compounds have undergone recent clinical trials and are shown to act as predicted by the HISS hypothesis. These therapeutic compounds represent a first-in-class therapy for treating prediabetic and diabetic insulin resistance and the metabolic syndrome. The synergistic antioxidant cocktail Samec offers a preventative approach to these metabolic diseases that should be tested in subjects at high risk for the development of diabetes. If HDIR represents the prediabetic stage of insulin resistance that accounts for the progression to full-stage diabetes and syndrome $\mathrm{X}$ (which we propose could be considered to be referred to as the AMIS syndrome), then the associated risk factors should benefit from efforts directed to early detection of HDIR and the subsequent abnormal MIS and to therapy for the prevention or reversal of AMIS and hence type 2 diabetes.

\section{Acknowledgments}

This study was funded by operating grants from the Canadian Institutes of Health Research and the Manitoba Health Research Council Regional Partnership Program. Manuscript preparation was by Karen Sanders. We acknowledge the excellent daily and long term care and monitoring of the animals provided by Gerry Nolette and the staff of Central Animal Care Services at the University of Manitoba. Related interests: W.W. Lautt and Z. Ming are inventors on a patent for the synergistic combination of $S$-adenosylmethionine, vitamin E, and vitamin C (Samec). Benac is licensed by the University of Manitoba to DiaMedica Inc., Winnipeg, Manitoba. Samec is licensed by the University of Manitoba to SciMar Ltd., Winnipeg, Manitoba.

\section{References}

Afonso RA, Ribeiro RT, Fernandes AB, Patarrão RS, Macedo MP. Hepatic-dependent and independent insulin actions are impaired in the obese Zucker rat model. Obesity (Silver Spring). 2007; 15(2):314-321. DOI: 10.1038/oby.2007.524 [PubMed: 17299103]

Barbieri M, Rizzo MR, Manzella D, Paolisso G. Age-related insulin resistance: is it an obligatory finding? The lesson from healthy centenarians. Diabetes Metab Res Rev. 2001; 17(1):19-26. DOI: 10.1002/dmrr.178 [PubMed: 11241888]

Björntorp P. Abdominal fat distribution and the metabolic syndrome. J Cardiovasc Pharmacol. 1992; 20(Suppl 8):S26-S28.

Boden G, Ruiz J, Urbain JL, Chen X. Evidence for a circadian rhythm of insulin secretion. Diabetes. 1996; 45:40A.

Borkan GA, Hults DE, Gerzof SG, Robbins AH, Silbert CK. Age changes in body composition revealed by computed tomography. J Gerontol. 1983; 38(6):673-677. [PubMed: 6630900]

Britton A, Shipley M, Malik M, Hnatkova K, Hemingway H, Marmot M. Changes in heart rate and heart rate variability over time in middle-aged men and women in the general population (from the Whitehall II Cohort Study). Am J Cardiol. 2007; 100(3):524-527. DOI: 10.1016/j.amjcard. 2007.03.056 [PubMed: 17659940]

Brownlee M. Biochemistry and molecular cell biology of diabetic complications. Nature. 2001; 414(6865):813-820. DOI: 10.1038/414813a [PubMed: 11742414] 
Cadenas E, Davies KJ. Mitochondrial free radical generation, oxidative stress, and aging. Free Radic Biol Med. 2000; 29(3-4):222-230. DOI: 10.1016/S0891-5849(00)00317-8 [PubMed: 11035250]

Chance B, Sies H, Boveris A. Hydroperoxide metabolism in mammalian organs. Physiol Rev. 1979; 59(3):527-605. [PubMed: 37532]

Corbett EK, Mary DA, McWilliam PN, Batten TF. Autonomic neuroscience: age-related loss of cardiac vagal preganglionic neurons in spontaneously hypertensive rats. Exp Physiol. 2007; 92(6): 1005-1013. DOI: 10.1113/expphysiol.2007.038216 [PubMed: 17644704]

Dela F, Kjaer M. Resistance training, insulin sensitivity and muscle function in the elderly. Essays Biochem. 2006; 42(1):75-88. DOI: 10.1042/bse0420075 [PubMed: 17144881]

Esteve JM, Mompo J, Garcia de la Asuncion J, Sastre J, Asensi M, Boix J, et al. Oxidative damage to mitochondrial DNA and glutathione oxidation in apoptosis: studies in vivo and in vitro. FASEB J. 1999; 13(9):1055-1064. [PubMed: 10336888]

Fitzgerald ME, Tolley E, Jackson B, Zagvazdin YS, Cuthbertson SL, Hodos W, Reiner A. Anatomical and functional evidence for progressive age-related decline in parasympathetic control of choroidal blood flow in pigeons. Exp Eye Res. 2005; 81(4):478-491. DOI: 10.1016/j.exer.2005.03.008 [PubMed: 15935343]

Frayn KN. Visceral fat and insulin resistance: causative or correlative? Br. J Nutr. 2000; 83(Suppl 1):S71-S77. DOI: 10.1017/S0007114500000982

Goodpaster BH, Thaete FL, Simoneau JA, Kelley DE. Subcutaneous abdominal fat and thigh muscle composition predict insulin sensitivity independently of visceral fat. Diabetes. 1997; 46(10):15791585. DOI: 10.2337/diabetes.46.10.1579 [PubMed: 9313753]

Goran MI, Bergman RN, Gower BA. Influence of total vs. visceral fat on insulin action and secretion in African American and white children. Obes Res. 2001; 9(8):423-431. DOI: 10.1038/oby. 2001.56 [PubMed: 11500522]

Grundy SM, Cleeman JI, Daniels SR, Donato KA, Eckel RH, Franklin BA, et al. Diagnosis and management of the metabolic syndrome: an American Heart Association/National Heart, Lung, and Blood Institute Scientific Statement. Circulation. 2005; 112(17):2735-2752. DOI: 10.1161/ CIRCULATIONAHA.105.169404 [PubMed: 16157765]

Guarino MP, Macedo MP. Co-administration of glutathione and nitric oxide enhances insulin sensitivity in Wistar rats. Br J Pharmacol. 2006; 147(8):959-965. DOI: 10.1038/sj.bjp.0706691 [PubMed: 16491098]

Guarino MP, Afonso RA, Raimundo N, Raposo JF, Macedo MP. Hepatic glutathione and nitric oxide are critical for hepatic insulin-sensitizing substance action. Am J Physiol Gastrointest Liver Physiol. 2003; 284(4):G588-G594. [PubMed: 12466146]

Harman D. Aging: a theory based on free radical and radiation chemistry. J Gerontol. 1956; 11(3):298300. [PubMed: 13332224]

Houstis N, Rosen ED, Lander ES. Reactive oxygen species have a causal role in multiple forms of insulin resistance. Nature. 2006; 440(7086):944-948. DOI: 10.1038/nature04634 [PubMed: 16612386]

Hunt JV, Dean RT, Wolff SP. Hydroxyl radical production and autoxidative glycosylation: glucose autoxidation as the cause of protein damage in the experimental glycation model of diabetes mellitus and ageing. Biochem J. 1988; 256(1):205-212. [PubMed: 2851978]

Hunt JV, Smith CC, Wolff SP. Autoxidative glycosylation and possible involvement of peroxides and free radicals in LDL modification by glucose. Diabetes. 1990; 39(11):1420-1424. DOI: 10.2337/ diabetes.39.11.1420 [PubMed: 2227114]

Ingall TJ, McLeod JG, O'Brien PC. The effect of ageing on autonomic nervous system function. Aust N Z J Med. 1990; 20(4):570-577. [PubMed: 2222350]

Inoue, M. Protective mechanism against reactive oxygen species. In: Arias, IM.Boyer, JL.Fausto, N.Jakoby, WB.Schachter, D., Shafritz, DA., editors. The liver: biology and pathobiology. 3. Raven Press; New York: 1994. p. 443-459.

Jablonski MM, Iannaccone A, Reynolds DH, Gallaher P, Allen S, Wang X, Reiner A. Age-related decline in VIP-positive parasympathetic nerve fibers in the human submacular choroid. Invest Ophthalmol Vis Sci. 2007; 48(2):479-485. DOI: 10.1167/iovs.06-0972 [PubMed: 17251439] 
Latour MG, Chan CC. A rapid insulin sensitivity test (RIST) in the anesthetized mice. Diabetes. 2002; 51(Suppl 2):A422. Abstr.

Latour MG, Lautt WW. Insulin sensitivity regulated by feeding in the conscious unrestrained rat. Can J Physiol Pharmacol. 2002; 80(1):8-12. DOI: 10.1139/y01-094 [PubMed: 11911229]

Lautt WW. Hepatic parasympathetic neuropathy as cause of maturity-onset diabetes? Gen. Pharmacol. 1980; 11(4):343-345.

Lautt WW. The HISS story overview: a novel hepatic neurohumoral regulation of peripheral insulin sensitivity in health and diabetes. Can J Physiol Pharmacol. 1999; 77(8):553-562. DOI: 10.1139/ cjpp-77-8-553 [PubMed: 10543718]

Lautt WW. Practice and principles of pharmacodynamic determination of HISS-dependent and HISSindependent insulin action: methods to quantitate mechanisms of insulin resistance. Med Res Rev. 2003; 23(1):1-14. DOI: 10.1002/med.10022 [PubMed: 12424750]

Lautt WW. A new paradigm for diabetes and obesity: the hepatic insulin sensitizing substance (HISS) hypothesis. J Pharmacol Sci. 2004; 95(1):9-17. DOI: 10.1254/jphs.95.9 [PubMed: 15153645]

Lautt WW. Postprandial insulin resistance as an early predictor of cardiovascular risk. Ther Clin Risk Manag. 2007; 3(5):761-770. [PubMed: 18473001]

Lautt WW, Wang X, Sadri P, Legare DJ, Macedo MP. Rapid insulin sensitivity test (RIST). Can J Physiol Pharmacol. 1998; 76(12):1080-1086. DOI: 10.1139/cjpp-76-12-1080 [PubMed: 10326829]

Lautt WW, Macedo MP, Sadri P, Takayama S, Duarte Ramos F, Legare DJ. Hepatic parasympathetic (HISS) control of insulin sensitivity determined by feeding and fasting. Am J Physiol Gastrointest Liver Physiol. 2001; 281(1):G29-G36. [PubMed: 11408252]

Lautt WW, Ming Z, Macedo MP, Legare DJ. HISS-dependent insulin resistance (HDIR) in aged rats is associated with adiposity, progresses to syndrome $\mathrm{X}$, and is attenuated by a unique antioxidant cocktail. Exp Gerontol. 2008; 43(8):790-800. DOI: 10.1016/j.exger.2008.04.013 [PubMed: 18538970]

Lebovitz HE. The relationship of obesity to the metabolic syndrome. Int J Clin Pract Suppl. 2003; 134(134):18-27.

Lindmark S, Lönn L, Wiklund U, Tufvesson M, Olsson T, Eriksson JW. Dysregulation of the autonomic nervous system can be a link between visceral adiposity and insulin resistance. Obes Res. 2005; 13(4):717-728. DOI: 10.1038/oby.2005.81 [PubMed: 15897481]

Mager DE, Wan R, Brown M, Cheng A, Wareski P, Abernethy DR, Mattson MP. Caloric restriction and intermittent fasting alter spectral measures of heart rate and blood pressure variability in rats. FASEB J. 2006; 20(6):631-637. DOI: 10.1096/fj.05-5263com [PubMed: 16581971]

Ming Z, Fan Y-J, Yang X, Lautt WW. Synergistic protection by $S$-adenosylmethionine with vitamins C and $E$ on liver injury induced by thioacetamide in rats. Free Radic Biol Med. 2006; 40(4):617-624. DOI: 10.1016/j.freeradbiomed.2005.09.034 [PubMed: 16458192]

Ming Z, Legare DJ, Lautt WW. Obesity, syndrome X, and diabetes: the role of HISS-dependent insulin resistance altered by sucrose, an antioxidant cocktail, and age. Can J Physiol Pharmacol. 2009; 87(10):873-882. DOI: 10.1139/Y09-079 [PubMed: 20052013]

Moore MC, Satake S, Baranowski B, Hsieh P-S, Neal DW, Cherrington AD. Effect of hepatic denervation on peripheral insulin sensitivity in conscious dogs. Am J Physiol Endocrinol Metab. 2002; 282(2):E286-E296. [PubMed: 11788359]

O'Brien IAD, O'Hare P, Corrall RJM. Heart rate variability in healthy subjects: effect of age and the derivation of normal ranges for tests of autonomic function. Br Heart J. 1986; 55(4):348-354. DOI: 10.1136/hrt.55.4.348 [PubMed: 3964501]

Patarrão RS, Lautt WW, Afonso RA, Ribeiro RT, Guarino MP, Fernandes AB, et al. Meal-induced insulin sensitization and its parasympathetic regulation in humans. Can J Physiol Pharmacol. 2008; 86(12):880-888. DOI: 10.1139/Y08-080 [PubMed: 19088809]

Phillips RJ, Powley TL. As the gut ages: timetables for aging of innervation vary by organ in the Fischer 344 rat. J Comp Neurol. 2001; 434(3):358-377. DOI: 10.1002/cne.1182 [PubMed: 11331534]

Phillips RJ, Powley TL. Innervation of the gastrointestinal tract: patterns of aging. Auton Neurosci. 2007; 136(1-2):1-19. DOI: 10.1016/j.autneu.2007.04.005 [PubMed: 17537681] 
Rebrin I, Bayne ACV, Mockett RJ, Orr WC, Sohal RS. Free aminothiols, glutathione redox state and protein mixed disulphides in aging Drosophila melanogaster. Biochem J. 2004; 382(Pt 1):131136. DOI: 10.1042/BJ20040506 [PubMed: 15142037]

Ribeiro RT, Lautt WW, Legare DJ, Macedo MP. Insulin resistance induced by sucrose feeding in rats is due to an impairment of the hepatic parasympathetic nerves. Diabetologia. 2005; 48(5):976-983. DOI: 10.1007/s00125-005-1714-6 [PubMed: 15830187]

Ribeiro RT, Afonso RA, Guarino MP, Macedo MP. Loss of postprandial insulin sensitization during aging. J Gerontol A Biol Sci Med Sci. 2008; 63(6):560-565. [PubMed: 18559629]

Robinson LE, Graham TE. Metabolic syndrome, a cardiovascular disease risk factor: role of adipocytokines and impact of diet and physical activity. Can J Appl Physiol. 2004; 29(6):808-829. [PubMed: 15630152]

Sadri P, Lautt WW. Blockade of nitric oxide production in the liver causes insulin resistance. Proc West Pharmacol Soc. 1998; 41:37-38. [PubMed: 9836234]

Sadri P, Lautt WW. Blockade of hepatic nitric oxide synthase causes insulin resistance. Am J Physiol. 1999; 277(1 Pt 1):G101-G108. [PubMed: 10409156]

Sadri P, Reid MAG, Afonso RA, Schafer J, Legare DJ, Macedo MP, Lautt WW. Meal-induced insulin sensitization in conscious and anaesthetized rat models comparing liquid mixed meal with glucose and sucrose. Br J Nutr. 2006; 95(2):288-295. DOI: 10.1079/bjn20051644 [PubMed: 16469144]

Sastre J, Pallardo FV, Vina J. Glutathione, oxidative stress and aging. Age (Omaha). 1996; 19(4):129_ 139. DOI: $10.1007 / \mathrm{BF} 02434082$

Schneider T, Hein P, Michel-Reher MB, Michel MC. Effects of ageing on muscarinic receptor subtypes and function in rat urinary bladder. Naunyn Schmiedebergs Arch Pharmacol. 2005; 372(1):71-78. DOI: 10.1007/s00210-005-1084-0 [PubMed: 16059734]

Singh I, Marshall MC Jr. Diabetes mellitus in the elderly. Endocrinol Metab Clin North Am. 1995; 24(2):255-272. [PubMed: 7656891]

Skrapari I, Tentolouris N, Perrea D, Bakoyiannis C, Papazafiropoulou A, Katsilambros N. Baroreflex sensitivity in obesity: relationship with cardiac autonomic nervous system activity. Obesity (Silver Spring). 2007; 15(7):1685-1693. DOI: 10.1038/oby.2007.201 [PubMed: 17636086]

Stern N, Izkhakov Y. The metabolic syndrome revisited: “cardiometabolic risk" emerges as common ground between differing views of the ADA and AHA. J Cardiometab Syndr. 2006; 1(5):362-363. DOI: 10.1111/j.1524-6175.2006.05999.x [PubMed: 17679794]

Taniguchi A, Nakai Y, Sakai M, Yoshii S, Hamanaka D, Hatae Y, et al. Relationship of regional adiposity to insulin resistance and serum triglyceride levels in nonobese Japanese type 2 diabetic patients. Metabolism. 2002; 51(5):544-548. DOI: 10.1053/meta.2002.31984 [PubMed: 11979383]

Tateishi N, Higashi T, Shinya S, Naruse A, Sakamoto Y. Studies on the regulation of glutathione level in rat liver. J Biochem. 1974; 75(1):93-103. [PubMed: 4151174]

Tewari HK, Gadia R, Kumar D, Venkatesh P, Garg SP. Sympathetic-parasympathetic activity and reactivity in central serous chorioretinopathy: a case-control study. Invest Ophthalmol Vis Sci. 2006; 47(8):3474-3478. DOI: 10.1167/iovs.05-1246 [PubMed: 16877418]

Tulloch-Reid MK, Hanson RL, Sebring NG, Reynolds JC, Premkumar A, Genovese DJ, Sumner AE. Both subcutaneous and visceral adipose tissue correlate highly with insulin resistance in African Americans. Obes Res. 2004; 12(8):1352-1359. DOI: 10.1038/oby.2004.170 [PubMed: 15340119]

von Känel R, Nelesen RA, Ziegler MG, Mausbach BT, Mills PJ, Dimsdale JE. Relation of autonomic activity to plasminogen activator inhibitor-1 plasma concentration and the role of body mass index. Blood Coagul Fibrinolysis. 2007; 18(4):353-359. DOI: 10.1097/MBC.0b013e3281139c67 [PubMed: 17473577]

Wolff SP, Bascal ZA, Hunt JV. “Autoxidative glycosylation”: free radicals and glycation theory. Prog Clin Biol Res. 1989; 304:259-275. [PubMed: 2675032]

Xie H, Lautt WW. Induction of insulin resistance by cholinergic blockade with atropine in the cat. J Auton Pharmacol. 1995; 15(5):361-369. DOI: 10.1111/j.1474-8673.1995.tb00402.x [PubMed: 8744976]

Xie H, Lautt WW. Insulin resistance of skeletal muscle produced by hepatic parasympathetic interruption. Am J Physiol. 1996; 270(5 Pt 1):E858-E863. [PubMed: 8967475] 


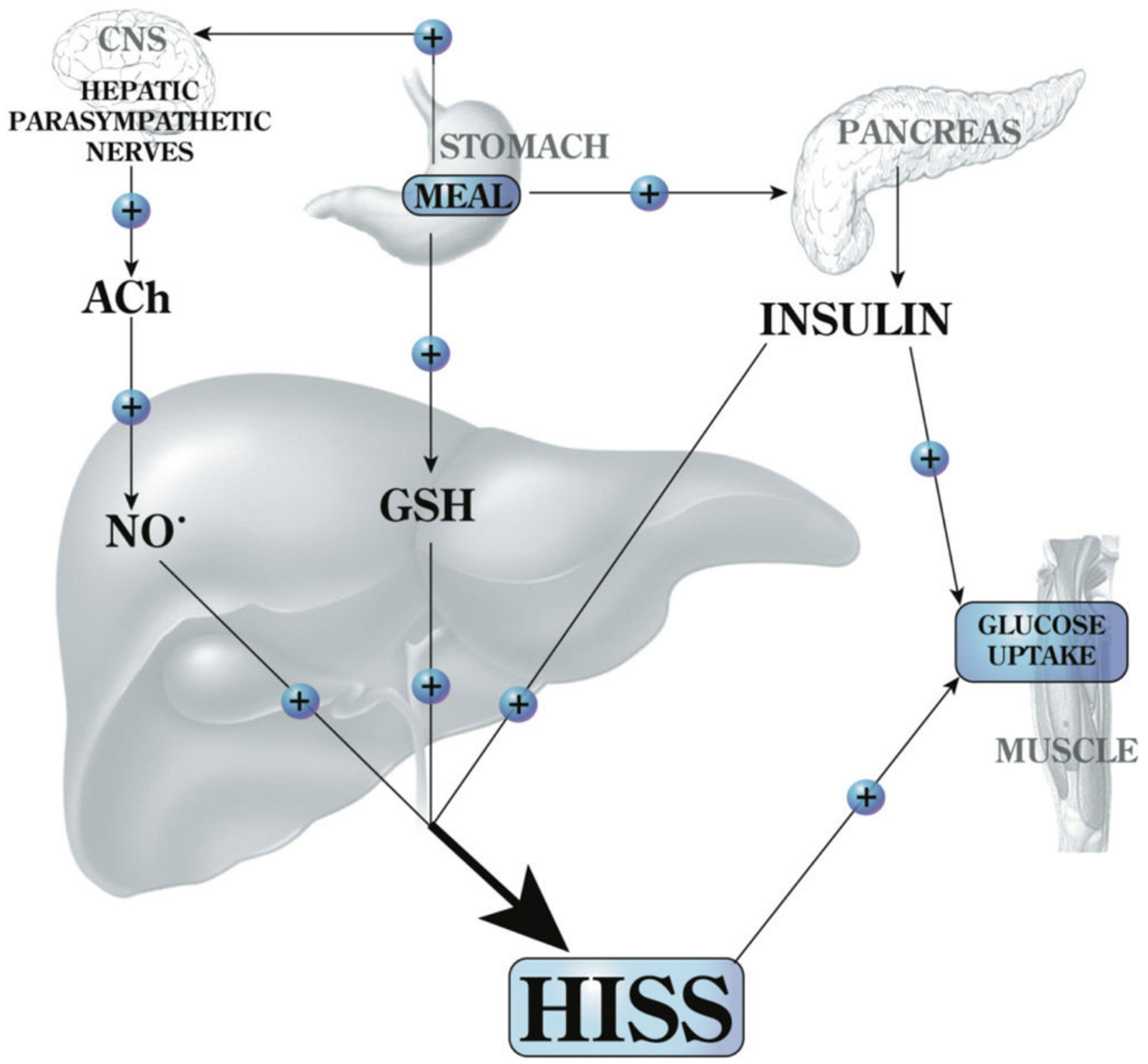

Fig. 1.

Feeding results in an increase of hepatic glutathione (GSH) and a parasympathetic signal to the liver that acts, via acetylcholine (ACh), on muscarinic receptors to activate NO release. Both of these signals are permissive and both are needed in order for insulin to cause the release of hepatic insulin-sensitizing substance (HISS). HISS acts selectively on skeletal muscle. Blockade of any portion of these pathways leads to blockade of HISS release and a state of HISS-dependent insulin resistance. Insulin resistance is physiologically regulated to occur in the fasted state, but when HISS release is not activated by feeding, its absence is suggested to account for postprandial hyperglycemia, hyperinsulinemia, hyperlipidemia, and increased oxidative stress. Chronic lack of HISS action results in a progressive and predictable series of homeostatic dysfunctions typical of type 2 diabetes. 

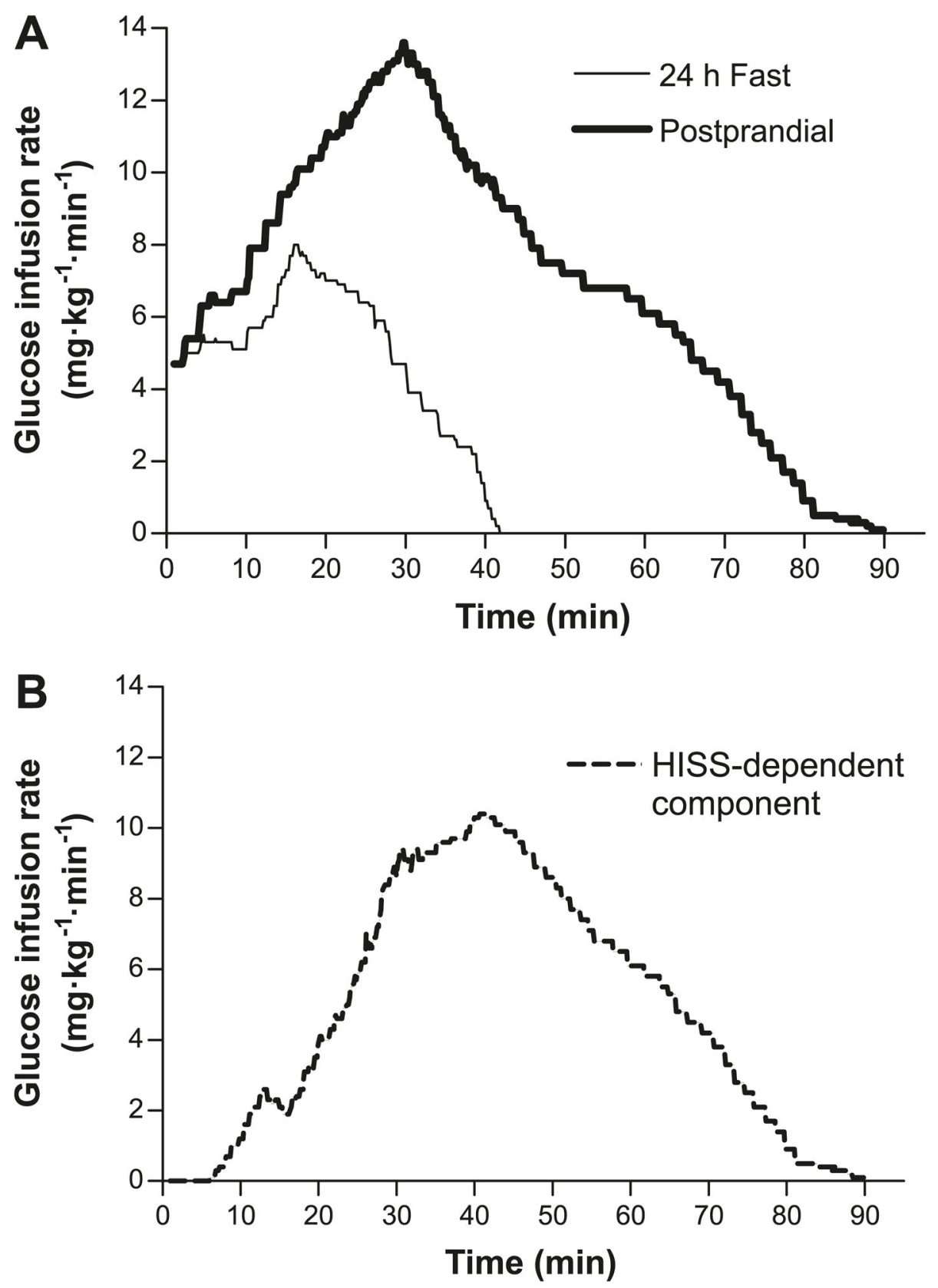

Fig. 2.

Mean profile using the dynamic analysis of the pattern of glucose infusion during the rapid insulin sensitivity test (RIST) in healthy human males. The mean RIST curves were obtained by averaging glucose infusion rates at 0.1 min intervals throughout the test. (A) Postprandial RIST (bold line) and the RIST obtained after $24 \mathrm{~h}$ fast (simple line). (B) Hepatic insulinsensitizing substance (HISS)-dependent component of insulin action, calculated from the difference between the curves in panel A. HISS action begins at $6.3 \pm 2.3 \mathrm{~min}$ after the onset of insulin administration and continues for 40-50 min after the direct action of insulin.

(From Patarrão et al. 2008, reproduced with permission of Can. J. Physiol. Pharmacol., Vol. 86, p. 884, (C) 2008 National Research Council Canada.) 


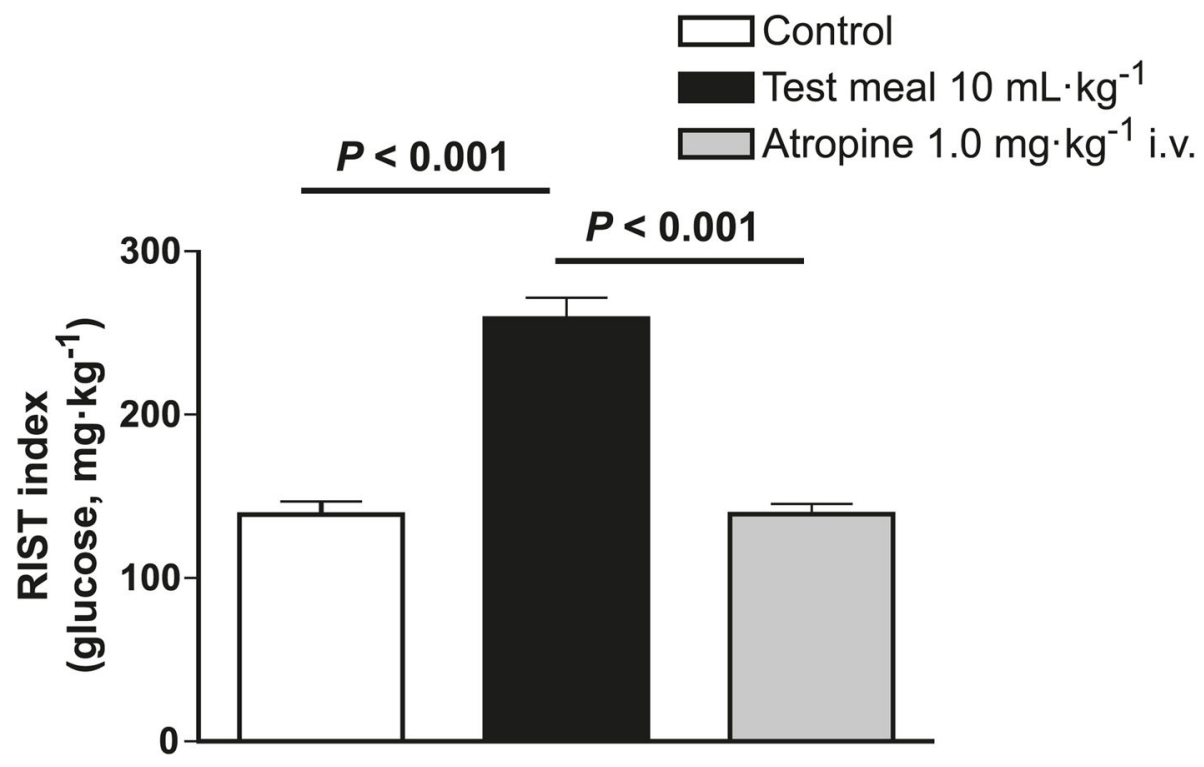

Fig. 3.

Demonstration of 2 methods for quantifying meal-induced insulin sensitization (MIS). The rapid insulin sensitivity test (RIST) was carried out in $24 \mathrm{~h}$-fasted rats. A liquid test meal was injected into the stomach via an implanted gastric catheter, and after a new glycemic baseline was established (90 min), a postprandial RIST was carried out. The increase in RIST index quantifies MIS. The second method is to perform the RIST in the fed state and then again after HISS release has been blocked by atropine. The response to insulin administration in conscious, unrestrained rats tested by using the RIST was increased by $90.5 \% \pm 20 \%$ after the liquid mixed meal. Atropine, which blocks HISS release, completely eliminated MIS ( $n=6)$. (From Sadri et al. 2006.) 

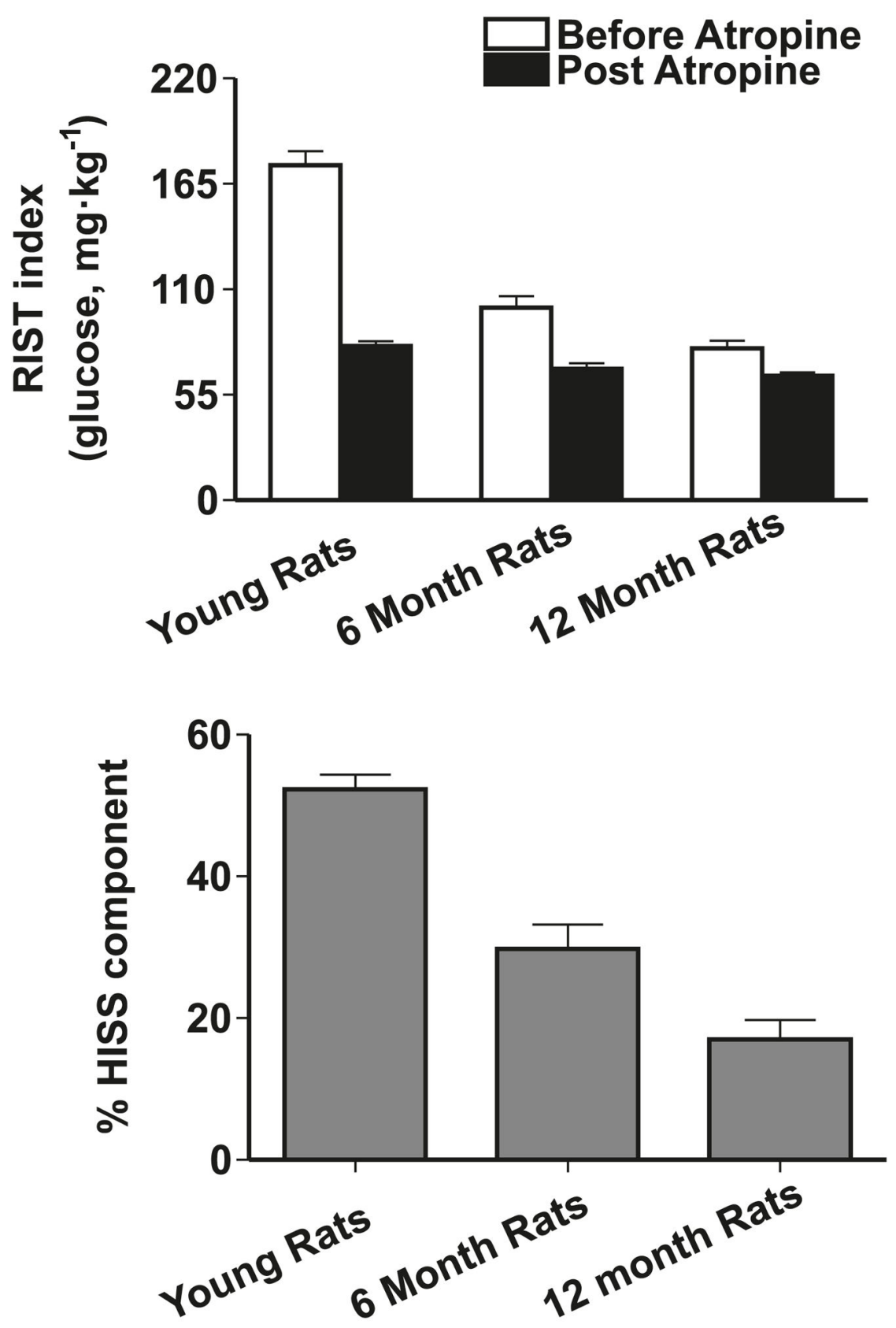

Fig. 4.

The rapid insulin sensitivity test (RIST) performed in fed rats represents both the direct action of insulin and the hepatic insulin-sensitizing substance (HISS)-dependent component of insulin action. Atropine blocks HISS release, so the post-atropine response is due entirely to the direct action of insulin. The lower panel shows the percentage of the total response attributed to HISS action. Comparison of the 3 age groups reveals that increasing age results in reduced dynamic response to insulin attributable to HISS action, with the HISSindependent (post-atropine) component of insulin action being modestly affected. (From Lautt et al. 2008, reproduced with permission of Exp. Gerontol., Vol. 43, p. 795, () 2008 Elsevier.) 


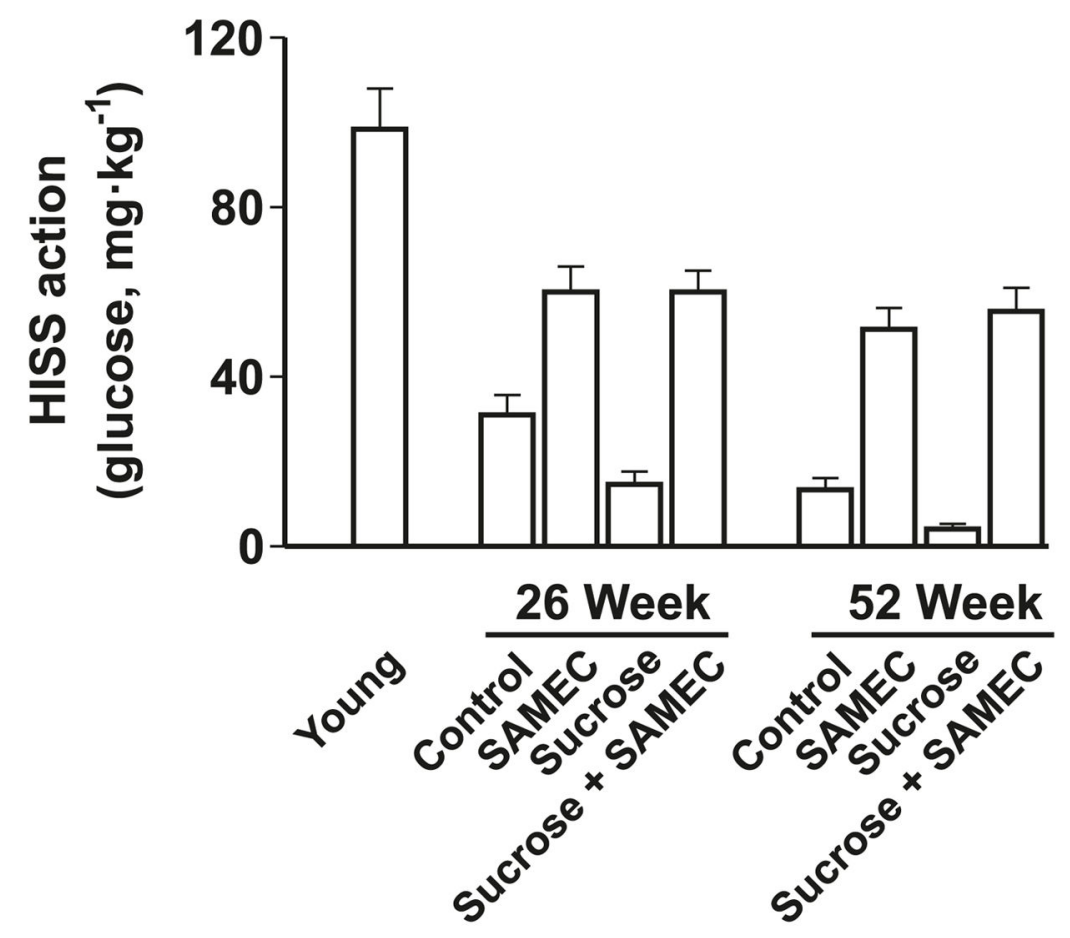

Fig. 5.

HISS-dependent insulin action assessed from the RIST index decreases with age in rats (young refers to 9 weeks of age) and is exacerbated by a low-dose (5\%) sucrose supplement. The antioxidant cocktail Samec attenuates the decline in HISS action resulting from age and completely prevents the impact of sucrose. Results were calculated from the pooled data of Lautt et al. 2008 and Ming et al. 2009. (From Lautt and Ming 2009, p. 330, reproduced with permission, () 2009 Routledge/Taylor \& Francis Group, LLC.) 


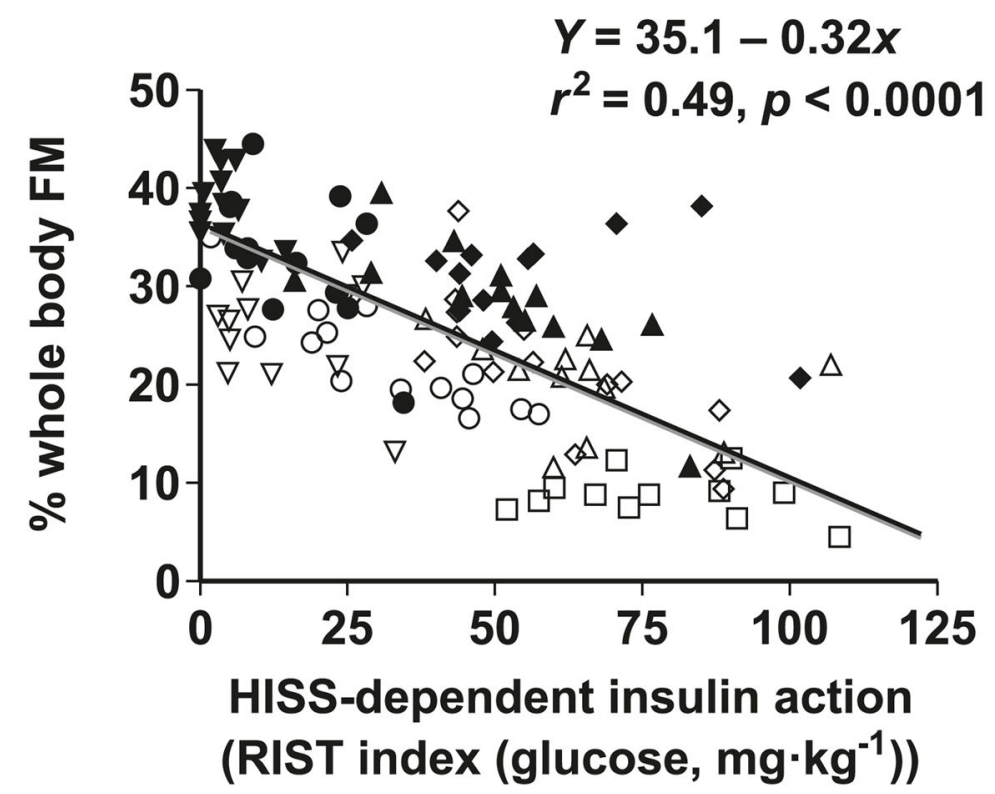

$\square$ Young

- 6 Month Control

- 12 Month Control

$\triangle 6$ Month SAMEC

\ 12 Month SAMEC

$\nabla 6$ Month Sucrose

$\nabla 12$ Month Sucrose

$\diamond 6$ Month Sucrose/SAMEC

- 12 Month Sucrose/SAMEC

Fig. 6.

Adiposity can be predicted from HISS action, shown by pooled data from normal aging rats (9 week, 6 month, and 12 month), age plus sucrose, age plus antioxidant (Samec), and age plus sucrose plus antioxidant (Samec). Whole-body fat mass (FM) was estimated from bioelectrical impedance but the relationship is similar for adiposity determined by measuring regional adiposity on the basis of weighed fat mass from perinephric, perienteric, and epididymal fat pads. As HISS action decreases, adiposity increases. Results were calculated from data in Lautt et al. 2008. (From Lautt and Ming 2009, p. 331, reproduced with permission, @2009 Routledge/Taylor \& Francis Group, LLC.) 


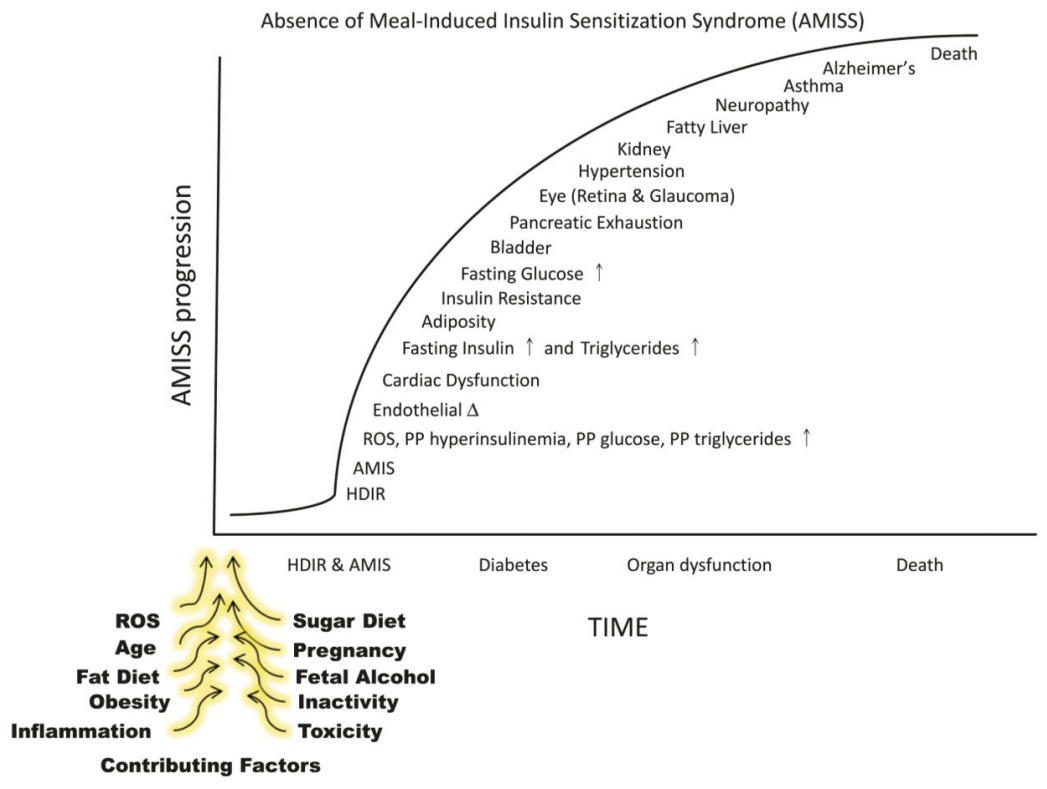

Fig. 7.

The absence of meal-induced insulin sensitization (AMIS) syndrome is the progressive accumulation of signs and symptoms of homeostatic disturbances caused by AMIS after each meal. HISS-dependent insulin resistance (HDIR) in the fasted state is appropriate, but if not rapidly reversed after a meal, leads to postprandial increases in glucose, insulin, lipids, and reactive oxygen species (ROS). The disease progresses to dysfunctions in major organ systems. The specific order of appearance of dysfunctions is an estimate that requires verification. The contributing factors that block HISS release and result in AMIS have been reviewed in Lautt 2003. 